\title{
HYPOTHERMIA ASSOCIATED WITH PNEUMONIA AND ACIDOSIS
}

\author{
R. H. Trefor Jones, M.B., Ch.B., D.C.H.
}

Ronald Finn, M.D., M.R.C.P.

\author{
R. E. Bourdillon, M.B., Ch.B., B.D.S., \\ M.R.C.P.
}

Kenneth Martindale, M.B., Ch.B.

\section{Case History}

J.M., aged 56 years, was admitted to the Intensive Therapy Unit at 4.0 a.m. on the morning of the 18 th of March 1965. He was a recluse who lived in a single-roomed fiat close to the hospital and had been found lying in a doorway in a small side-street nearby. It was ascertained that he had been in this position for at least two hours before his admission. The temperature in Liverpool at that time was $5.4^{\circ} \mathrm{C}$ $\left(41^{\circ} \mathrm{F}\right)$.

On admission he was unconscious, pale, slightly cyanosed and corpse-like. His rectal temperature was $83^{\circ} \mathrm{F}$. The peripheral pulses were not palpable and a blood pi essure recording could not be obtained. His respiration was rapid (28 per min.) and shallow. Examination of his chest revealed that the air entry to all areas was poor. There was marked diminution of air entry in the left lower lobe with evidence of consolidation. The tendon jerks were depressed generally and it was noted that he had a withered right arm (this was later found to be due to an injury received in childhood).

When he eventually recovered it was established that he had been feeling unwell for a few days prior to his admission. He had only a vague recollection of what had occurred on the day of his admission but remembered feeling very weak and being unable to walk without staggering. He was under the impression that he had left his room at 2.0 p.m. with the intention of reaching the hospital.

Investigations: Chloride, 92; Potassium, 4.3; Sodium, $132 \mathrm{mEq} / 1$; Blood sugar $20 \mathrm{mg}$; urea, $75 \mathrm{mg} / 100 \mathrm{ml}$;; Serum Amylase, 320 Units '(normal, 70-180 Units). OSF normal except for a low sugar level $(15 \mathrm{mg} / 100$ $\mathrm{ml}$.) which reflected the blood sugar. ECG showed the presence of auricular fibrillation and ' $\mathrm{J}$ ' waves. The ventricular rate was $90 / \mathrm{min}$. Chest $\mathrm{x}$-ray: bilateral basal consolidation with generalised pulmonary oedema. There was also evidence of an old fibrotic tuberculous lesion in the left apex and of chronic bronchitis and emphysema. Hb. $52 \%$ (7.6 g.); PCV $31 \%$; MCHC 25\%; WBC 22,000/cu. mm., neut, 17,000 ; lymphs 2,800 , monos. 450 . In addition the film showed large numbers of normoblasts $(1,300 / \mathrm{cu}$. $\mathrm{mm}$.). Treatment: Endotracheal intubation was carried out and respiration was performed initially by a Boyle's machine. The hypoglycaemia was corrected by giving $80 \mathrm{~g}$. of $50 \%$ dextrose solution i.v. but there was no marked change in his condition following this.
The blood sugar rose to $320 \mathrm{mg} / 100 \mathrm{ml} .100 \mathrm{mg} 3$ hydrocortisone was administered i.v., and i.v. fluids were commenced with $5 \%$ dextrose containing 200 $\mathrm{mg}$. of hydrocortisone $/ 540 \mathrm{ml}$.

During the three hours following admission his condition remained unchanged. Active warming was not carried out and he was left at room temperature and covered lightly with four blankets.

At the end of three hours blood gas analysis showed the following results: $\mathrm{PcO}_{2} 48 \mathrm{~mm}$. Hg., pH 7.04, Base Deficit $=-13 \mathrm{mEq}$. In view of the severe degree of acidosis it was felt that an attempt should be made to correct this by the administration $\vec{\bullet}$ of sodium bicarbonate. The amount was calculate 8 from the formula $0.3 \mathrm{x}$ Base $\mathrm{x}$ Weight (in $\mathrm{kgg}$ ? (Mellemgaard and Astrup, 1960) and a total $150 \mathrm{mEq}$. was given intravenously over a period of one hour.

Thirty minutes following the initiation of this therapy there was a dramatic recovery of consciousness which occurred almost abruptly. At the end of this time the blood gas values were as follows: Pco: $29 \mathrm{~mm}$. Hg., pH 7.466 Base $-2 \mathrm{mEq}$.

During the ensuing two hours the blood pressure gradually returned to normal limits and there was a reversion of the ECG to sinus rhythm with disappearance of the ' $J$ ' waves. His temperature within six hours of admission was $94^{\circ} \mathrm{F}$ rising gradually for a further 24 hours until it reached normality.

Antibiotic therapy had been commenced initially with chloramphenicol $250 \mathrm{mg}$ i.m. every six hours and penicillin, two million units i.m. every six hours. After three days the chloramphenicol was discontinued.

Progress: In view of the low haemoglobin two pints of blood were transfused on the second day and the $\mathrm{Hb}$. rose to $65 \%$.

It was noted that the urinary output on the first day was $600 \mathrm{ml}$, with a further decrease to $450 \mathrm{ml}$. on the second day. There was a corresponding rise in the blood urea from 75 to $145 \mathrm{mg} / 100 \mathrm{ml}$. During the second day he developed paroxysms of hiccoughing and also frequent myoclonic twitches. A pericardial friction rub was heard along the lower left sternal edge.

It was also noted that he had developed an icteric tinge and the serum bilirubin was $2.3 \mathrm{mg} / 100 \mathrm{ml}$. Blood was taken at this time for estimation of cold agglutinins and for Coombs' testing but no antibody was detected.

There was a small rise in urinary output on the 


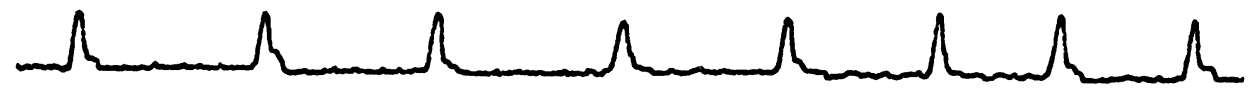

FIG. 1.-(a) Shows the typical changes of hypothermia with "J" waves and auricular fibrillation.

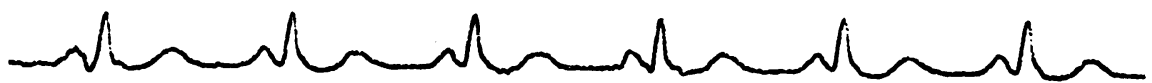

(b) Shows reversion to sinus rhythm 30 minutes after correction of the acidosis.

third day with a fall in blood urea. During the ensuing four days his renal function improved and the blood urea fell to $54 \mathrm{mg} / 100 \mathrm{ml}$.

The initial pulmonary oedema had cleared by the second day and the pneumonia responded to the antibiotic therapy.

\section{Discussion}

This case illustrated several important points both in diagnosis and treatment.

1. Hypothermia. He presented with the classical features of hypothermia including the corpse-like feel, auricular fibrillation, ' $J$ ' waves on the ECG tracing, absent peripheral pulses and hypotension. (Duguid, Simpson, and others, 1961; EmslieSmith, 1958; Rosin and Exton-Smith, 1964). Although there was no clinical evidence of pancreatitis the serum amylase was raised; a finding previously described by Read, Emslie-Smith, Gough and Holmes (1964) and McNicol and Smith (1954).

Active rewarming was not employed and his temperature rose to normal within 12 hours.

2. Hypoglycaemia. Kedes and Field (1964) have described hypothermia in association with hypoglycaemia. Hypoglycaemia is recognised by paediatricians in cases of 'cold injury' in the neonate (Mann and Elliott. 1957). It is of interest however that hypoglycaemia is not mentioned in several of the most recent reports of hypothermia in adults. We feel that the recognition of severe hypoglycaemia in this case may well have contributed to his recovery.

3. Metaholic Acidosis. Both metabolic and respirator $\mathrm{V}$ acidosis have been described in hypothermia. (McNicol and Smith (1964), Brewin, Gould, Nashat and Neil (1955)). Most authors have suggested that it is not severe enough to require active treatment. The metabolic acidosis is due to tissue anoxia, and it becomes rapidly worse as the patient is rewarmed and lactic acid and other acid products pass from the tissues into the circulation. This aggravation of acidosis with re-establishment of the peripheral circulation is well known to anaesthetists under the name of 'rewarming acidosis' (Nisbet, 1964). The situation is therefore analagous to the potentially fatal fall in serum potassium in the recovery from diabetic acidosis. It therefore follows that blood gas analyses as performed by most workers in the initial stages of profound hypothermia do not give a true picture. The $\mathrm{pH}$ in our case was 7.04 (this result was not corrected for temperature and is therefore slightly low) three hours following admission when the temperature was beginning to rise. The correction of the acidosis was followed by immediate recovery of consciousness and the ECG reverted to sinus rhythm with disappearance of the ' $J$ ' waves. The blood pressure and peripheral pulses also returned rapidly to normalo limits; a factor which has been reported pre-? viously in the treatment of acidosis accompanying cardiac arrest by Stewart (1964). Addis, Thomson and Welch (1964) describe the rapid return to consciousness following the treatment of diabetic ketosis with bicarbonate.

4. Acute Renal Failure. The renal failure was presumably due to the effects on the kidney of hypothermia, hypotension and acidosis. Although of moderate severity it resolved spontaneously without active treatment. The haemolytic anaemia which was severe enough to require transfusion may have been associated with the acute renal failure described in the "haemolytic uraemic syndrome' (Gasser, Gautier, Steck, Siebenmann and Oechslin, 1955). It is also possible that the pneumonic process may have contributed to the haemolysis although we were not able to demonstrate cold agglutinins subsequently.

\section{Summary}

A case of pneumonia is described complicated by hypothermia, metabolic acidosis, hypoglycaemia, renal failure and haemolytic anaemia. It is suggested that the recognition and management of the hypoglycaemia and metabolic acidosis contributed to the recovery in this case. We believe that these two conditions are not uncommon in accidental hypothermia, and their recognition and 
treatment should improve the otherwise poor prognosis of these cases as reported in previous studies.

We would like to thank Dr. R. W. Brookfield and Dr. C. M. Ogilvie, for their permission to publish this case, Dr. C. A. St. Hill for his assistance and the nursing staff of the Intensive Therapy Unit.

\section{REFERENCES}

Addis, G. J., Thomson, W. S. T., and Welch, J. D. (1964): Bicarbonate Therapy in Diabetic Acidosis, Lancet, ii, 223.

BrewiN, 'E. G., Gould, R. P., Nashat, F. S., and NeIL, E. (1955): The Investigation of Problems of Acid-base Equilibrium in Hypothermia, Guy's Hosp. Rep., 104, 177.

Duguid, H., SimPSON, R. G., and Stowers, J. M. (1961): Accidental Hypthermia, Lancet, ii, 1213.

EMSLIE-SMITH, D. (1958): Accidental Hypothermia - a Common Condition with a Pathognomonic Electrocardiogram, Lancet, ii, 492.

Gasser, V. C., Gautier, E., Steck, A., SiebenmanN,
R. E., and OechSLIN, R. (1955): Hamolytischuramische Syndrome, Bilaterale Nierenrindernekrosen bei Akuten Erworbenen Hamolytisch Anamien, Schweiz med. Wschr., 85, 905.

KeDES, L. H., and FIELD, J. B. (1964): Hypothermia a Clue to Hypoglycaemia, New Engl. J. Med., 271, 785.

ManN, T. P., and ElliotT, R. I. K. (1957): Neonatal Cold Injury Due to Accidental Exposure to Cold, Lancet, $i, 229$.

McNicol, M. W., and SMith, R. (1964): Accidental Hypothermia, Brit. med. J., i, 19.

MellemgaARD, K., and AstruP, P. (1960): The Quantitative Determination of Surplus Amounts of Acid or Base in the Human Body, Scand. J. clin. Lab. Invest., 12, 187.

NiSBET, H. I. A. (1964): Acid-Base Disturbances in Hypothermia, Int. Anaesth. Clin., 2, No. 4, 847.

Read, A. E., EmSlie-Smith, D., Gough, K. R., and Holmes, R. (1961): Pancreatitis and Accidental Hypothermia, Lancet, ii, 1219.

Rosin, A. J., and Exton-Smith, A. N. (1964): Clinical Features of Accidental Hypothermia with Some Observation on Thyroid Function, Brit. med. J., i, 16 .

\title{
MALIGNANT TUMOURS OF MECKEL'S DIVERTICULUM
}

\author{
Case Report of a Leiomyosarcoma and a Review of the Literature \\ Kenneth J. Carroll, M.B., B.S.(Qld.), F.R.C.S.(Eng.), F.R.C.S.(Edin.)* \\ Surgical Registrar, Royal Berkshire Hospital, Reading
}

Malignant tumours arising in a Meckel's Diverticulunı are so rare as to be regarded as surgical and pathological curiosities. There have been only two previously reported cases in the British literatuure (Aird, 1952; Barrett, 1954). A number of papers exist in the American literature and the best review is that of Weinstein, Dockerty and Maugh (1963), who, in a collective review reported a total of 35 cases of sarcoma arising from a Meckel's Diverticulum.

\section{Case Report}

B.P.,male, aged 50, was admitted as an emergency on $3 / 9 / 64$ with abdominal pain of 36 hours duration. He was well until two days previously when he awoke at night, shaking and sweating. The following morning he was weak but othenwise well. Twelve hours later he developed continuous upper abdominal pain which later spread to the lower abdomen, being worse on the left side. The pain remained constant and did not radiate further. He was more comfortable when lying still and it hurt to cough. There was anorexia and nausea but no vomiting. There had been a loose bowel action on the day of admission. There were no previous similar episodes.

\section{*Present address:}

Surgical Registrar, North Brisbane Hospital, Brisbane.
On examination he was afebrile, pulse 100, BP 130/ $80 \mathrm{~mm}$. Hg. He was in some pain and his tongue was thickly coated. There was no adenopathy. The abdomen was distended but there was no visible peristalsis. There was tenderness on both sides of the lower abdomen with marked rebound tenderness. Bowel sounds were diminished. There was no abdominal tumour palpable and no rigidity. Rectal examination revealed soft faeces, but no masses were palpable. The serum amylase was normal.

Operation. At operation what appeared to be a gangrenous Meckel's diverticulum was found, and this was removed by simple excision as the small intestine around the neck of the diverticulum was found to be healthy. The regional lymph nodes were not enlarged and the appendix was normal, as was the pelvic colon. There was no peritonitis. The abdomen $\frac{7}{0}$ was closed without drainage and antibiotics given post-operatively as well as intravenous therapy and $N$ naso-gastric suction. Recovery was uneventful.

Pathological Report: "The specimen consists of a $N$ piece of tissue stated to be a Meckel's diverticulum. N It is composed of necrotic tissue and dense white $\omega$ tissue which has the macrosoopic appearance of neoplasm. In the centre of the specimen there is a space 0 which appears to be lined by mucous membrane. At $\frac{D}{\Phi}$ one point the tumour appears to have broken through of the outer surface of the specimen, which again appears to be part of a bowel wall. Histological examination $\frac{7}{3}$ shows the mucous membrane is in fact gastric mucous membrane and the rest of the specimen is composed of $\stackrel{\mathbb{Q}}{\overparen{D}}$ 